\title{
Double the jeopardy: Balancing maternal and fetal risk during cardiac surgery
}

\author{
Leora B. Balsam, MD, and Abe DeAnda, Jr, MD
}

See related article on pages 607-10.

Pregnancy and cardiac surgery are an unusual pairing that pose risk of mortality and complication to the mother and fetus. Evidence is scant to guide best practices in this area, but those in the field agree that the hormonal and hemodynamic changes of pregnancy can exacerbate certain cardiovascular disease conditions. Accelerated aortic aneurysm growth has been noted in pregnant women with connective tissue disorders. This growth can result in acute aneurysm rupture and/or dissection. In the later stages of pregnancy, decompensated heart failure may develop in patients with native valve disorders as a consequence of the circulatory changes of pregnancy (increased cardiac output, increased circulating plasma volume, and relative anemia). In addition, hypercoagulability in pregnancy can result in acute valve thrombosis in patients with pre-existing mechanical valves, leading to rapid and life-threatening decompensation.

Cardiovascular disease is the leading cause of maternal mortality in industrialized countries, ${ }^{1}$ so prenatal counseling is clearly imperative for women with known cardiovascular diagnoses. Ideally, patients with connective tissue disorders should undergo screening for aortic pathology, and corrective cardiac surgery should be performed before pregnancy, when indicated. Aortic root dimensions $>4.0 \mathrm{~cm}$ in patients with Marfan syndrome have been associated with an increased risk of acute aortic dissection during pregnancy ${ }^{2}$ and are an indication for a valve-sparing procedure. Clinicians providing prenatal care should be familiar with the historical and physical features of connective tissue disorders, so that individuals at risk can be identified, screened, and counseled appropriately. Similarly, prenatal counseling is important for individuals with valvular disease, congenital heart disease, and/or a history of cardiac surgery. These patients may develop cardiovascular decompensation in the later stages of pregnancy, even if they are asymptomatic before pregnancy.

From New York University, Langone Medical Center, New York, NY. Disclosures: Authors have nothing to disclose with regard to commercial support. Received for publication Nov 18, 2014; accepted for publication Nov 19, 2014. Address for reprints: Leora B. Balsam, MD, NYU Langone Medical Center, 530 First Ave, Suite 9V, New York, NY 10016 (E-mail: leora.balsam@nyumc.org). J Thorac Cardiovasc Surg 2015;149:611-2 $0022-5223 / \$ 36.00$

Copyright (c) 2015 by The American Association for Thoracic Surgery http://dx.doi.org/10.1016/j.jtcvs.2014.11.057
In this issue of the Journal, Yates and colleagues ${ }^{3}$ present their experience with surgery of the aortic valve and aorta in pregnancy. All of the cases were performed in the second trimester, and the circulatory strategies used are similar to those that have been described previously by these authors and others. ${ }^{4,5}$ The principles are as follows: (1) Avoid cardiac surgery in the first trimester during the period of fetal organogenesis; (2) Optimize uteroplacental perfusion by using a high-flow, high-pressure, normothermic perfusion strategy during cardiopulmonary bypass; and (3) Employ continuous fetal and uteroplacental monitoring and make adjustments to the cardiopulmonary bypass strategy in the presence of hypoperfusion and/or fetal bradycardia.

Ample clinical evidence indicates that the risk of fetal demise during maternal cardiac surgery is significantly higher at an earlier gestational age. As a consequence, surgery is avoided in early pregnancy when medically feasible. The specific perfusion strategies used during cardiac surgery in pregnancy are modified to optimize fetal and uteroplacental perfusion. Optimal perfusion occurs at normothermia with perfusion pressures $>70 \mathrm{~mm}$ Hg. Hypoperfusion is further minimized by avoiding vasopressors, excessive hemodilution, and long periods of cardiopulmonary bypass and cardioplegic arrest. In addition, these authors ${ }^{3}$ utilize pulsatile flow during cardiopulmonary bypass, as it has proven beneficial in an experimental ovine model of fetal perfusion. ${ }^{6,7}$ Mechanistically, this may be due to release of endothelialderived vasodilators in the presence of pulsatility.

How to balance what is best for the mother with what is best for the fetus is indeed an ethical and clinical dilemma. For the mother, standard surgical approaches, including appropriate use of hypothermia, cardioplegic arrest, and deep hypothermic circulatory arrest, offer the best chance of success. Yet all of these strategies pose risk to the fetus. Hypothermia impairs uteroplacental perfusion and results in uterine contraction. Systemic hyperkalemia causes fetal bradycardia and distress. Deep hypothermic circulatory arrest most often leads to fetal loss, although anecdotal cases of survival to full term, without developmental abnormalities, have been described. Yates and colleagues ${ }^{3}$ present a clinical strategy that is a compromise aimed at achieving what is best for the fetus while providing a reasonable standard of care for the mother.

Available alternatives must be considered in these cases. Can surgery be delayed until the third trimester or until the 
gestation is full term? If so, cardiac surgery can be performed after the delivery, either in the same setting or soon thereafter. This strategy improves the chances of the neonate surviving, but it adds risk for the mother, who must withstand the hemodynamic stresses of late pregnancy. Another alternative is to proceed with maternal surgery using standard techniques, regardless of gestational age, with the understanding that saving the life of both the mother and fetus may not be possible. Whenever possible, it is paramount that the clinician discuss the risks, benefits, and alternatives with the mother, and help her navigate the difficult decisions regarding the goals of surgery and its timing.

Lastly, although their article is entitled "Perioperative Management and Outcomes of Aortic Surgery During Pregnancy," this particular series includes only patients with aortic valve, aortic root, and ascending pathologyall of which were treated with a normothermic perfusion strategy with aortic clamping and cardioplegic arrest. Such strategies would not be practical for more complex aortic procedures. We are severely limited in our ability to treat conditions of the aorta that require deep hypothermic circulatory arrest in these patients when the focus is on both maternal and fetal survival. This area is one that may benefit from experimental research to identify safer operations that meet the needs of both mother and fetus.

\section{References}

1. Nickens M, Long R, Geraci S. Cardiovascular disease in pregnancy: (women's health series). South Med J. 2013;106:624-30.

2. Immer FF, Bansi AG, Immer-Bansi AS, McDougall J, Zehr KJ, Schaff HV, et al. Aortic dissection in pregnancy: analysis of risk factors and outcome. Ann Thorac Surg. 2003;76:309-14.

3. Yates MT, Soppa G, Smelt J, Fletcher N, van Besouw JP, Thilaganathan B, et al. Perioperative management and outcomes of aortic surgery during pregnancy. J Thorac Cardiovasc Surg. 2015;149:607-10.

4. Jahangiri M, Clark J, Prefumo F, Pumphrey C, Ward D. Cardiac surgery during pregnancy: pulsatile or nonpulsatile perfusion. J Thorac Cardiovasc Surg. 2003; 126:894-5.

5. John AS, Gurley F, Schaff HV, Warnes CA, Phillips SD, Arendt KW, et al. Cardiopulmonary bypass during pregnancy. Ann Thorac Surg. 2011;91:1191-7.

6. Champsaur G, Parisot P, Martinot S, Ninet J, Robin J, Ovize M, et al. Pulsatility improves hemodynamics during fetal bypass. Experimental comparative study of pulsatile versus steady flow. Circulation. 1994;90:47-50.

7. Champsaur G, Vedrinne C, Martinot S, Tronc F, Robin J, Ninet J, et al. Flow-induced release of endothelium-derived relaxing factor during pulsatile bypass: experimental study in the fetal lamb. J Thorac Cardiovasc Surg. 1997; 114:738-44. 